\title{
SELLING, DELIVERY AND TRADE MARKETING - AN OPERATIONAL TRIDENT OF THE DISTRIBUTION SYSTEM
}

\author{
Ioana Olariu \\ "Vasile Alecsandri” University of Bacau \\ ioana_barin_olariu@yahoo.com
}

\begin{abstract}
This paper highlights the way in which a distribution system can be made operational in FMCG, starting from the interaction between three components of the system: selling, delivery and trade marketing. On this basis, I have categorized the improvement opportunities of each component, using the appropriate key performance indicators (KPIs) of the system objectives. The optimal configuration of instruments and successful interaction of these components, improve the distribution system contribution to company performance. A specific system, defined for solving marketing problems, must be designed according to this purpose, and in this regard, all the significant elements and relationships must be subordinate to the objective by which it will achieve the desired solution. Business objectives achievement can be measured as effectiveness - the degree to which objectives were achieved, or as efficiency - the degree to which objectives have been achieved in the available resources. For evaluating the effectiveness with which an operative marketing system turns its sources into necessary results to solve a problem, it requires certain criteria to measure performance. These three elements: selling, delivery and trade marketing, are a trident of distribution which can lead to an optimal approach of market opportunities.
\end{abstract}

\section{Keywords}

key performance indicators; selling; delivery; trade marketing

\section{JEL classification}

M31

\section{Defining performance measures}

If choosing an alternative action or alternative systems of marketing actions that are to be made on a rational basis, it is necessary to measure the degree to which various alternatives meet predetermined objectives, or, in other words, measuring the effects that these alternatives have on the objectives.

Specifying a measure for efficiency and effectiveness performance of the decision, is closely related to determining the objectives and constraints which are always embedded in a composite endpoint. Since the problem structuring phase, is imperative to define measurements for the action alternatives performance.

KPIs are analytical indicators, selected as the most illustrative in monitoring key activities and processes for organizations, providing an overview on performance.

Using KPIs facilitate organizational learning, improve key operations, capabilities and processes, enabling decision makers to work towards achieving the desired results.

Distribution system objectives are:

- Distribution system selected by outlet groups should be made operational for Selling; Delivery and Trade Marketing;

- To ensure common understanding of the key considerations in making the chosen system operational;

- To agree issues related to selling. The Key Performance Indicators (KPIs) are the following: sales force deployment; sales forecasting and order management; 
- To agree issues related to delivery. Agreed KPIs are the following: network structure and product flows; transportation; warehousing and inventory management.

- To agree issues related to Trade Marketing. The KPIs are the following: Point Of Purchase (POP); merchandising and trade promotions.

The appropriate indicators which correspond to these goals, highlights the results of each component. For their shape are needed inputs that are ordered by sections according the below sequence.

\section{Selling}

\subsection{Overview Sales force Deployment}

The objective is to serve each segment in the market (outlet groups, channels, outlet types) with a targeted sales approach, appropriate resources and organization, tailored sales force skills, incentives and support.

Required Inputs are:

- Distribution system selection by outlet group;

- Retail data;

- Sales forecast.

Key Performance Indicators are: call duration by outlet type and call frequency by outlet and route. The purpose of these two indicators is to track actual calls versus requirements.

Another indicator is represented by the effective calls by representatives. The purpose is to monitor sales representative effectiveness.

The last Key Performance Indicators are objective versus actual sales and planned versus actual calls. The purpose of these two indicators is to check target fulfillment of sales force.

\subsection{Overview Sales Forecasting}

The objective is to implement an accurate sales forecast with a clear consensus process (to agree on “one number”) and interfaces to planning activities.

Required Inputs are historic sales data.

Sales forecasting data are important inputs for: inventory management; sales goals and order management.

Two approaches are recommended for sales forecast:

- Bottom up (primarily built on field data) is short term, serves as input for delivery planning;

- Top down (based on bottom up data and assumptions for demand change) is long term and is used for asset decisions and budgeting.

Forecasting strongly depends on the market. New markets without historic data have to rely on assumptions, other countries' experiences, available data etc.

Established markets can rely on historic data, unless they select a new distribution system.

Key Performance Indicators are sales forecast error and variability of sales forecast compared to demand variability. The purpose of these indicators is to measure sales forecasting accuracy.

\subsection{Overview Order Management}

The objective is to customise order taking procedures and conditions by outlet group, implement a smooth order management process and provide the best practice cash management according to the conditions in the market. 
Required Inputs are:

- Distribution System Selection by outlet group

- Credit/Accounts receivable history by customer

This document concentrates on managerial issues, relating to order management.

Key Performance Indicators are the following: order frequency by customer and order size by customer. The purpose of these indicators is to track actual orders versus requirements.

Other indicators are the percent of orders on time and the percent of order fill. The purpose of these indicators is to monitor order effectiveness.

The last indicator is represented by working capital utilization (the sum of the cost of inventory plus trade credit), whose purpose is to measure the working capital employed in the company's trading activities.

\section{Delivery}

\subsection{Overview Network Structure \& Product Flow}

The objective is to establish an effective and efficient network of facilities (distribution centres, warehouses and depots), thereby improving product flows, shortening delivery time and decreasing out-of-stocks. Network structure refers to physical location of distribution system components. It is different from route structure, which is a sales and transportation management issue.

Required Inputs are:

- Distribution system selection

- Sales forecasting

- Current network cost

Optimisation of network structure is precondition before warehousing, transportation and inventory management can be improved. While the network optimisation can be approached through spreadsheet modelling/linear programming, only a specific software program will provide ideal solutions with limited efforts.

A Key Performance Indicator is the number of deliveries/day (planned versus actual), whose purpose is to track delivery performance against targets.

Other Key Performance Indicators are percent of deliveries on time and percent of volume delivered on time. The purpose of these indicators is to monitor delivery effectiveness.

Other KPIs are the following: the drop size - track actual drop size versus requirements and the number of drops/route per customer type - the purpose is to monitor route performance

The last indicator is the percent of out-of-stocks in distribution centres/at retail, whose purpose is to measure "out-of-stocks" as key critical distribution measure in delivery.

\subsection{Transportation}

Operationalising transportation involves evaluating both infrastructure and processes. The objective is to determine the appropriate resources, routes, depth of transportation function ownership and monitoring mechanisms to effectively deliver products to the customers.

Required Inputs are: distribution system selection by outlet type/channel; current network structure and outsourcing decisions; retail data and Customer Satisfaction Measurements (CSM).

Making transportation operational applies only if the delivery and transportation activities are assumed directly by a specific company or controlled by that. There are two dimensions of transportation: 
- Primary transportation: from factory to warehouse/distribution centre;

- Secondary transportation: from distribution centre to retail/wholesale.

Primary transportation Key Performance Indicators are the following: percent of ontime deliveries; percent of vehicle capacity utilization and percent of fleet utilization. The purpose of these first indicators is to monitor effectiveness of transportation.

Other primary transportation Key Performance Indicators are the following: percent of product losses and percent of damaged product. The purpose of these indicators is to track product loss.

The last KPI is the percent of cost / km, which measures transportation efficiency.

Secondary transportation Key Performance Indicators are: the percent of invoices not delivered; percent of on-time deliveries; percent of complete deliveries and percent of vehicle capacity utilization. The purpose of these indicators is to monitor effectiveness of transportation.

Another indicator is the number of calls / day, whose purpose is to track product loss. The last indicators are the cost / call and cost / km, whose purpose is to measure transportation efficiency.

\subsection{Overview Warehousing}

The objective is to determine the appropriate storage equipment, storage space design, layout design, warehousing technology, and warehouse material handling processes to effectively and efficiently expedite movement of products through the warehouses Required Inputs are:

- Distribution system selection by outlet type/channel

- Current network structure and outsourcing decisions

Making warehousing operational applies only if the warehousing activities are assumed directly by a specific company.

There are five dimensions in warehousing:

The first one is layout design; the question whose answer must be found is Which facility layout will minimize total product movement and retrieval times?

The second one is storage space design: the question whose answer must be found is What design will enable efficient capacity usage?

The third one is storage equipment: the question whose answer must be found is What type of racking is most appropriate?

The fourth one is handling technology: the question whose answer must be found is What type of handling equipment is most appropriate?

The last dimension of warehousing is represented by finished goods handling processes: the question whose answer must be found is Which should be the warehousing processes and how should they be organized to effectively and efficiently move products in the warehouses?

Key Performance Indicators are: percent of floor space utilization; percent of cube space utilization (warehouse capacity utilization). The purpose of these indicators is to track effectiveness of warehouse layout.

Other KPIs are percent of out of stocks in warehouses (measure out-of-stock as key distribution effectiveness indicator); percent of product losses in warehouses; percent of product damages in warehouses; percent of orders with picking errors; average vehicle unloading time and average vehicle loading time. The purpose of these indicators is to monitor effectiveness of material handling.

The purpose of the last two KPIs: average orders/operator/day and average vehicles/operator/day, is to check the operator performance.

\subsection{Overview Inventory Management}

The objective is to maintain appropriate inventory levels to ensure sufficient stocks under all circumstances while minimising inventory carrying costs. 
Required Inputs are: distribution system selection; sales forecasting and operational design of other "Delivery" components.

Inventory management must be operational in conjunction with transportation and warehousing, as all of them involve mutual tradeoffs in effectiveness and efficiency.

A Key Performance Indicator is the percent of accuracy of inventory (physical versus system) - the purpose of this indicator is to monitor inventory accuracy.

The purpose of other KPIs indicators, such as inventory level at distribution centre counter to target; forward stock in outlet and inventory holding cost, which measures inventory costs; is to track inventory levels (control of targets).

\section{Trade Marketing}

Tailor trade promotions and merchandising to outlets according to the strategy, set and monitor performance, define activities and responsibilities and co-ordinate purchase of material.

Required Inputs are:

- Distribution system selection

- Marketing/brand plan

- Retail Classification

- Sales forecasting

Key Performance Indicators are: percent of share of shelf at outlets; percent of floor space in outlets; facing in outlets and percent of stores with basic planograms.

The purpose of these indicators is to monitor effectiveness of merchandising activities.

Planned counter to actual promotions / merchandising - the purpose is to measure implemented value-added distribution against targets.

The purpose of knowing the percent of returns and store checks is to track freshness.

The choice of these performance indicators is a crucial stage in the analysis process, because the final result will depend on them, representing the basis on which the final decision regarding the distribution strategy will be taken. For evaluating the effectiveness with which an operative marketing system turns its sources into necessary results to solve a problem, it requires certain criteria to measure performance. These three elements: selling, delivery and trade marketing, are a trident of distribution which can lead to an optimal approach of market opportunities.

\section{References}

Ballou, R.H. (1992) Business logistics management: third edition, Englewood Cliffs, New Jersey: Prentice-Hall International, Inc.

Daellenback, H. (1994) System and decision-making; a management science approach, John Wiley \& Sons.

Gary L. L.; Kotler, Ph., Sridhar Moorthy K. (1992) Marketing Models, Prentice Hall Inc.

Lapin, L. (1991) Quantitative Methods for Business Decisions - with Cases, Harcourt Brace Jovanovich Publishers and its subsidiary, Academic Press.

Oakshott, L. (1997) Business Modelling and Simulation, Pitman Publishing.

Rosenbloom, B. (1991) Marketing channels. A management view: 4-th edition, Chicago: The Dryden Press.

Stasch, S.F. (1972) System analysis for marketing planning and control, Glenview, Scott, Foresman and Comp.

Stern, L., W. \& El-Ansary A.I. (1996) Marketing channels: 5-th edition, Upper Saddle, NJ: Prentice-Hall International, Inc. 